\title{
Post funduplication esophagogastric fistula, case report and radiologic findings
}

\begin{abstract}
Esophagogastric fistula is an extremely rare complication of Nissen fundoplication surgery. Progressive dysphagia and odynophagia are the most frequent symptoms reported. Diagnosis is usually made two or three years after surgery, and although endoscopy is the gold standard to confirm diagnosis, radiologic barium swallow typically shows an image of a double column at the lower third of the esophagus and must be recognized as pathognomonic in patients with dysphagia after Nissen fundoplication. We report the first case completely resolved by laparoscopy and we recommend this approach in selected cases.
\end{abstract}

Keywords: gastroesophageal fistula, laparoscopy, nissen fundoplication, radiologic image, barium swallow
Volume 5 Issue I - 2018

\begin{abstract}
Alejandro Weber Sánchez,' Pablo Weber Alvarez,' ${ }^{2}$ Carlos Bravo Torreblanca,' Denzil Garteiz Martinez,' Rafael Carbó Romano ${ }^{5}$

'Department of General Surgery, Universidad Anáhuac México, México

${ }^{2}$ Hospital Ángeles Lomas, Universidad Anáhuac México, México ${ }^{3}$ Department of General Surgery, Universidad La Salle, México
\end{abstract}

Correspondence: Luis Alejandro Weber Sánchez, Vialidad de la Barranca s/n C4I0,Valle de las Palmas, Huixquilucan, 52763, Estado de México, México, Tel 52469527,

Email awebersanchez@gmail.com

Received: August 29, 2017 | Published: February 08, 2018

\section{Introduction}

Esophagogastric fistula is an extremely rare complication of Nissen fundoplication that may have several origins. Because of the low incidence of this pathology it is difficult to recognize. The diagnosis is usually made after two or three years after the procedure probably due to the late development of symptoms. We were able to find only 15 cases reported in the literature, and this explains why there is little experience with this pathology and its radiologic findings. As far as we know, this is the first report of a post fundoplication fistula that has been resolved by laparoscopy. Emphasis is made on the radiologic diagnosis due to its importance in problem recognition and usefulness in planning the surgical procedure.

\section{Case report}

A 35year-old male with no prior relevant history underwent laparoscopic Nissen fundoplication two years before due to esophagogastric reflux, esophagitis and hiatal hernia. The surgery apparently had no complications but the patient presented dysphagia since the early postoperative period that did not improve despite medical treatment. Apparently no endoscopic dilatations were made, and the patient was started on proton pump inhibitors with mild response.

Ten months later he developed epigastric pain, irradiated to the back, mainly with food intake. An abdominal ultrasound reveled lithiasic cholecystitis. An esophagogram showed the passage of a double column of contrast material into the stomach and esophagogastric fistula was suggested (Figure 1). Endoscopy showed a diverticulum at the lower third of the esophagus with an impacted food bezoar that was extracted with foreign body tweezers and a fistulous path was found which communicated with the fundoplicated gastric fundus and confirmed the diagnosis (Figure 2). Due to the exacerbation of the symptoms, laparoscopic surgery was proposed to resolve both the gallbladder and the fistulous problems. The fundoplication was dismantled and the resection of the fistulous tract (Figure $3 \&$ Figure 4) was performed at the lower third of the esophagus with articulated linear stapler. Fibrin sealant (Tissucol ${ }^{\circledR}$ ) was applied to the proximal end of the fistulous tract, the closure was reinforced with suture in the gastric end of the resected fistula, Nissen fundoplication was done in the usual way (Figure 5) and finally cholecystectomy was performed. Recovery was uneventful with relief of dysphagia and odynophagia. At 5 year follow-up, the patient is asymptomatic without reflux and without dysphagia.

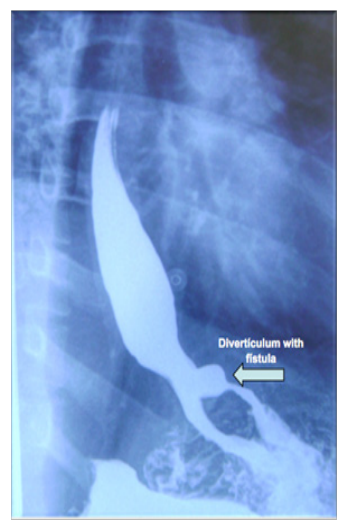

Figure I Esophagogram with double column of barium image.

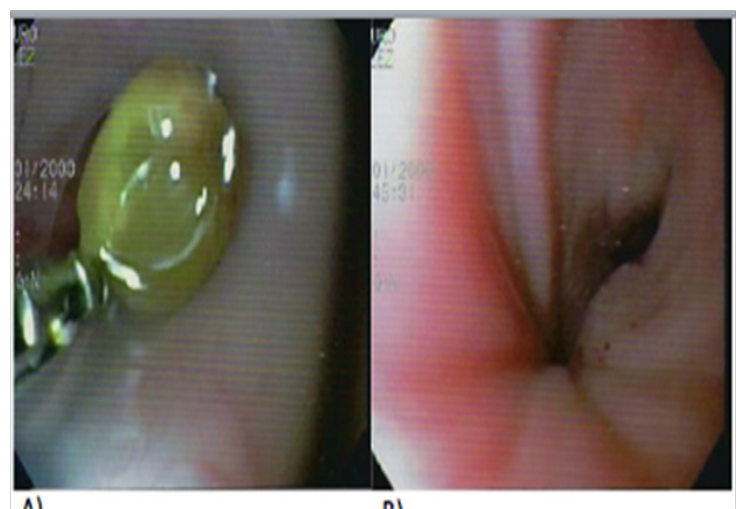

A)

B)

Figure 2 Endoscopic images:A) bezoar extraction B) Fistula orifice. 


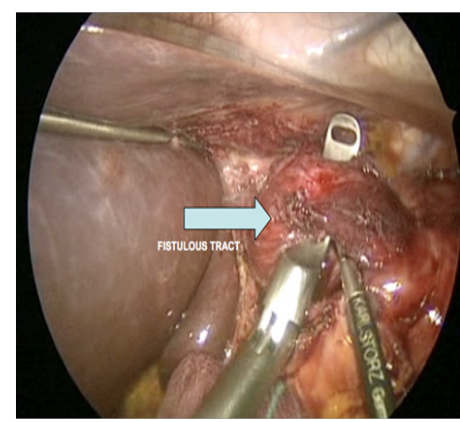

Figure 3 Dissected fistulous tract.

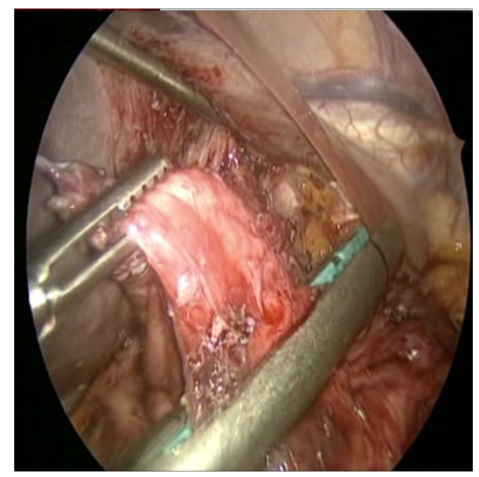

Figure 4 Closure of the fistula with linear stapler.

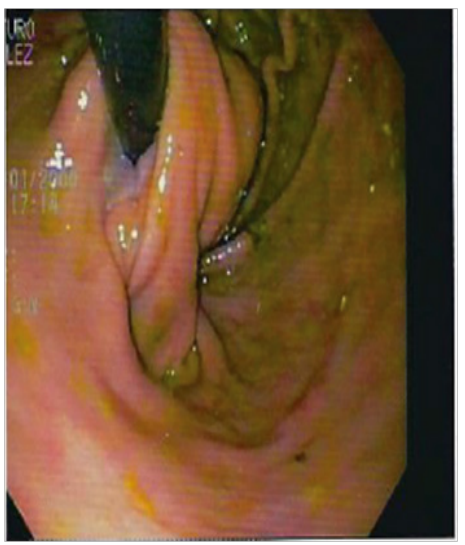

Figure 5 Endoscopic view of the fundoplicature.

\section{Discussion}

The most commonly known esophageal fistulas are those that communicate the esophagus to the trachea and are usually birth defects. The abnormal communication between the esophagus and the stomach is a very unusual situation that occurs as a complication in postoperative fundoplicated patients. Until now only 15 cases have been reported in the literature. ${ }^{1}$

Factors mentioned as related to this problem are preexisting esophageal ulcers that later erode the esophageal wall, persistent gastroesophageal reflux due to fundoplication failure, ${ }^{2,3}$ esophageal carcinoma ${ }^{4}$ or even Crohn's disease. ${ }^{5}$ There is little mention about failures during surgery such as those that cause necrosis around the fixation suture points for the fundoplication, ${ }^{6-8}$ trauma during dissection or inadequate traction of the esophagus or stomach without free perforation, but that erode the esophageal or gastric wall causing small infections that finally give rise to the fistula. This phenomenon is a probable cause in the case reported with the use of suture with pledgets for the fundic plicature. ${ }^{8}$
Some of these patients have received medical treatment with pump inhibitors to alleviate symptoms and although endoscopic clip application to close the fistula has been reported, surgery is the most effective treatment to close the fistula, and redo the Nissen fundoplication. ${ }^{2,9,10}$ All the cases described in the literature solved the problem by open surgery, but we believe that minimal-invasive surgery can be a better approach. In experienced hands, laparoscopy is a good therapeutic option because it allows dismantling the previous surgery and performing the new fundoplication with minimal complications and the benefits of mini-invasive surgery. It permits accurate visualization of the fistulous tract and allows its adequate resection with a better postoperative recovery. Endoscopic assistance as used in this case can be useful. As far as we know, this is the first case described of a total laparoscopic correction of this problem.

In most cases the diagnosis occurs two to three years after the first procedure. This may be due to the fact that, unlike esophageal or gastric perforation, the fistula does not cause an acute problem and symptoms of persistent dysphagia and odynophagia following antireflux surgery are progressive and are mainly attributed to other causes.

Although endoscopy is the gold standard for diagnosis, the radiologic image in the esophagogram seems to be constant in all reported cases. All show a double column of contrast material ${ }^{1,4}$ at the lower third of the esophagus as it enters the stomach. Because of this image, the condition has been named in some of the reports as "double lumen esophagus". We think that the pathognomonic feature of the esophagogram that must be recognized is this double column at the lower third of the esophagus in patients with dysphagia after Nissen fundoplication. Tomography is a useful instrument for the study of fistulas, but in this particular case it was not necessary due to the evidence obtained with the barium esophagogram study wich we consider pathognomonic.

\section{Acknowledgements}

None.

\section{Conflict of interest}

Author declares that there is no conflict of interest.

\section{References}

1. Tafen M, Tehrani N, Anoushiravani AA, et al. Esophagogastric fistula complicating Nissen fundoplication. Journal of Pediatric Surgery Case Reports. 2016;10:14-16.

2. Mihas AA, Slaughter RL, Goldman, LN, et al. Double Lumen Esophagus Hue To Reflux Esophagitis With Fibrous Septum Formation. Gastroenterology. 1976;71(1):136-137.

3. Raymond JI, Khan AH, Cain LR, et al. Multiple esophagogastric fistulas resulting from reflux esophagitis. Am $J$ Gastroenterol. 1980;73(5):430-433.

4. Fleming JL, DiMagno EP. Double lumen esophagus: presentation of esophagogastric fistula, a rare complication of fundoplication. Dig Dis Sci. 1986;31(1):106-108.

5. Rholl JC, Yavorski RT, Cheney CP, et al. Esophagogastric fistula: a complication of Crohn's diseaseecase report and review of the literature. $\mathrm{Am}$ J Gastroenterol. 1988;93(8):1381-1383.

6. Mullen JT, Burke EL, Diamond AB. Esophagogastric fistula. A complication of combined operations for esophageal disease. Arch Surg. 1975;110(7):826-828. 
7. Choudhry U, Shenoy V, Choudhry R, et al. Double-lumen esophagus: formation of a new lumen or septation of the existing one? South Med J. 1996;89(5):538-541.

8. Baladas HG, Smith GS, Richardson MA, et al. Esophagogastric fistula secondary to teflon pledget: a rare complication following laparoscopic fundoplication. Dis Esophagus. 2000;13(1):72-74.
9. Samiullah S, Samad F, Tang YM, et al. Double lumen esophagus: a rare complication of gastroesophageal reflux disease. Dig Endosc. 2014;26(2):282-284.

10. Hussain SZ, Abbas AE, Brown MF, et al. Surgical reconstruction of the double lumen esophagus. J Pediatr Surg. 2013;48(3):661-664. 